EVIDENCE BASED PUBLIC HEALTH POLICY AND PRACTICE

\title{
Income inequality and health: multilevel analysis of Chilean communities
}

\author{
S V Subramanian, I Delgado, L Jadue, J Vega, I Kawachi
}

J Epidemiol Community Health 2003;57:844-848

See end of article for authors' affiliations

.....................

Correspondence to:

Dr S V Subramanian,

Department of Health and

Social Behavior, Harvard

School of Public Health,

677 Huntington Avenue,

7th Floor, Boston MA

02115, USA:

svsubram@

hsph.harvard.edu

Accepted for publication 14 April 2003

Study objective: The evidence supporting the effect of income inequality on health has been largely observed in societies far more egalitarian than the US. This study examines the cross sectional multilevel associations between income inequality and self rated poor health in Chile; a society more unequal than the US.

Design: A multilevel statistical framework of 98344 people nested within 61978 households nested within 285 communities nested within 13 regions.

Setting: The 2000 National Socioeconomic Characterization Survey (CASEN) data from Chile.

Participants: Adults aged 18 and above. The outcome was a dichotomised self rated health 10 if very good, good or average; 1 if poor, or very poor). Individual level exposures included age, sex, ethnicity, marital status, education, employment status, type of health insurance, and household level exposures include income and residential setting (urban/rural). Community level exposures included the Gini coefficient and median income.

Main results: Controlling for individual/household predictors, a significant gradient was observed between income and poor self rated health, with very poor most likely to report poor health (OR: 2.94) followed by poor (OR: 2.77), low (OR: 2.06), middle (OR: 1.73), high (OR: 1.38) as compared with the very high income earners. Controlling for household and community effects of income, a significant effect of community income inequality was observed (OR:1.22).

Conclusions: Household income does not explain any of the between community differences; neither does it account for the effect of community income inequality on self rated health, with more unequal communities associated with a greater probability of reporting poor health.

W hile Preston ${ }^{1}$ and Rodgers ${ }^{2}$ were among the first to present an empirical ecological association between life expectancy and income inequality at the international level, fresh impetus to examine this association came from studies carried out within rich countries, ${ }^{3}$ sparked by Wilkinson's seminal paper in $1992 .{ }^{4}$ Ecological studies carried out both across countries ${ }^{4}$ and within countries ${ }^{56}$ have demonstrated a correlation between income inequality and lower life expectancy. The "income inequality hypothesis" posits that the distribution of income in society, over and above individual/household incomes, matters for population health. In other words, individual life expectancy depends not just on how much income individuals (or households) have, but also on the distribution of incomes within the society in which individuals reside.

In recent years, a number of multilevel studies have been published investigating the link between income inequality and a variety of health outcomes, ranging from mortality, ${ }^{7-14}$ self rated health, ${ }^{5}{ }^{15-21}$ health behaviours, ${ }^{22}$ and depressive symptoms. ${ }^{21}$ Of the 16 such studies published to date, the number of studies that found no association between income inequality and health after controlling for individual/household income $(n=9)$ have slightly outnumbered the studies that did find evidence for a contextual effect of income inequality $(\mathrm{n}=7)$. The growing number of null studies recently prompted a comment in an editorial in the British Medical Journal that the evidence for the income inequality hypothesis was "slowly dissipating". ${ }^{23}$

Such a conclusion seems premature as the international evidence not supporting a link between income inequality and health outcomes have (so far) been carried out in societies that are more egalitarian than the United States (the support, meanwhile, has been very strong within the United States $^{13} 16_{24}^{25}$ ), and moreover have welfare state protections that are more far reaching than in the US-for example, Japan, Sweden, Denmark, New Zealand, and even the UK.

There is a need, then, to test the income inequality hypothesis on large samples within countries that are more inegalitarian than the rich OECD countries (including the USA). The aim of this paper is to develop an explicitly multilevel test of the links between household income, community income, and income inequality on individual health in Chile. Chile provides a particularly interesting case study, as it is far more unequal than the United States (having implemented neoliberal economic advice from the Chicago School during the 1980s and 1990s). The country also maintains an excellent health information system, making it an ideal testing ground for the income inequality hypothesis. With an average life expectancy of over 75 years in 2000, and a per capita income of about US \$5000, Chile presents a society in an advanced stage of the epidemiological and economic transition.

Five related, yet distinct, hypotheses that capture the multilevel aspects of the health/income relation ${ }^{26}$ are addressed in this study:

- that self rated health improves with increase in household incomes (the absolute income hypothesis);

- that the relation between household income and self rated health varies across communities (community contingent individual absolute income hypothesis);

- that self rated health improves as the community in which the individual lives becomes richer (community absolute income hypothesis);

- that self rated health deteriorates as the community in which the individual lives becomes unequal (community income inequality hypothesis); and 
- that there is a cross level interaction between community income inequality and household income, such that the most adverse effect of income inequality is on poor individuals, while it may not have any impact on rich individuals (or may even be beneficial) (individualcommunity interaction hypothesis).

The income inequality/health relation question is thus intrinsically multilevel, whereby the causal processes (income differences, here) are hypothesised simultaneously at two levels, individual and community, with possible interaction between the two.

\section{METHODS}

We used data from the 2000 National Socioeconomic Characterization Survey (CASEN) from Chile. ${ }^{27}$ CASEN is a national, population based survey (representative at the community level) carried out by the Ministry of Planning since 1985 to describe the socioeconomic situation as well as the impact of social programmes on the living conditions of the Chilean population. The sample data for the analysis consisted of 98344 people aged 15 and older who belong to a random sample of 61978 households from 285 communities across the 13 regions of Chile (table 1 ).

The 2000 CASEN for the first time included a question on self rated health for the population aged 15 and above. Self rated health was determined by people's response to the question, "In general, would you say your health is very good, good, average, poor, very poor, don't know, don't want to answer?" For the analyses we excluded the last two categories and collapsed the remaining five categories to form a dichotomous outcome of self rated health: 0 for very good, good, and average; and 1 for poor or very poor. This was done to make our study comparable to the previous studies of self reported health, all of which have considered them in a dichotomous manner. In the final sample, about $8.7 \%$ reported being in very poor/poor health. A similar question was included in a different survey, "Living conditions of the population" carried out by the National Statistical Institute and Ministry of Health, and similar proportions were observed..$^{28}$

Table 1 provides a summary of the individual/household and community level variables used for the analysis. At the household level, equivalised monthly household income (in US\$) - our primary household level predictor of interestreported by respondents was categorised into very poor (less than \$30); poor $(\$ 30-60)$; low $(\$ 60-200)$; middle $(\$ 200-$ 500); high (\$500-1000); and very high (more than \$1000). We adopted the equivalisation procedure that is used in the Luxembourg Income Study - that is, to divide the household income by the square root of the number of household members. The categorisation at the lower end of the income spectrum (very poor and poor) reflects the official definition of poverty in Chile, while the remaining categories correspond broadly with local perception of income scales. We also examined other key individual socioeconomic and demographic predictors of self rated health including age, gender, ethnicity, marital status, educational attainment, employment status, type of health insurance and household urban/ rural residential affiliation. In Chile, there are two "ethnicities"; the first relates to those who have Spanish roots and the other relates to the Mapouches, almost without a mixture. The Mapouches are the minority and equate to what can be considered as the indigenous people. At the community level, the Gini coefficient was used to measure income inequality. ${ }^{29}$ The potential value of the Gini ranges between 0 to 1 , with 0 representing a society with no income inequality and 1 representing societies with perfect inequality. The Gini coefficient for the 285 communities was calculated from the per capita household income data of the 2000 CASEN survey using the Stata program. While calculating the Gini we accounted for the sampling design and weights associated with the survey.

Multilevel statistical techniques provide a technically robust analytical framework when the causal processes that affect the outcome are hypothesised to operate at more than one level simultaneously. ${ }^{26}{ }^{30}$ We conducted a multilevel regression analysis with 98344 people at level 1, nested

Table 1 Descriptive univariate information on the 2000 National Socioeconomic Characterization Survey (CASEN) data sample used for the analytical multilevel models

\begin{tabular}{|c|c|c|}
\hline \multicolumn{3}{|l|}{ Response } \\
\hline Poor/very poor health $(n=8513,8.7 \%)$ & Poor $(n=7732,7.9 \%)$; very poor $(n=781,0.8 \%)$ & $\begin{array}{l}\text { Very good }(n=7353,7.5 \%) ; \text { good }(n=51144 \text {, } \\
52 \%) \text {; average }(n=31334,31.9 \%)\end{array}$ \\
\hline \multicolumn{3}{|l|}{$\begin{array}{l}\text { Level 1: Individuals, } \mathrm{n}=98344 \\
\text { Individual level predictor variables }\end{array}$} \\
\hline Age $(y)$ & Mean $=43$ years & Range $=15-99$ years \\
\hline Gender & Base: male $(n=36609 ; 37.2 \%)$ & Contrast: female $(n=61735 ; 62.8 \%)$ \\
\hline Marital status & Base: couple $(n=61923 ; 63 \%)$ & $\begin{array}{l}\text { Contrast: single }(n=24312 ; 24.7 \%) \text {; separated/ } \\
\text { divorced }(n=4964 ; 5 \%) \text {; widowed }(n=7145 ; 7.3 \%)\end{array}$ \\
\hline Ethnic & Base: non-ethnic $(n=7714 ; 7.8 \%)$ & Contrast: ethnic $(n=90630 ; 92.2 \%)$ \\
\hline Years of education & Mean $=8$ years & Range $=0-21$ \\
\hline Type of health insurance & Base: private $(n=9425 ; 9.6 \%)$ & $\begin{array}{l}\text { Contrast: public }(n=77505 ; 78.8 \%) \text {; other } \\
(n=11414 ; 11.6 \%)\end{array}$ \\
\hline Economic activity status & Base: employed ( $n=39209,39.9 \%)$ & $\begin{array}{l}\text { Contrast: unemployed ( } n=4767,4.8 \%) \text {; inactive } \\
(n=54368,55.3 \%)\end{array}$ \\
\hline \multicolumn{3}{|l|}{ Level 2: Households, $n=61978$} \\
\hline Equivalised monthly household income (in US\$) & Base: very high, more than $1000(n=3509 ; 3.6 \%)$ & $\begin{array}{l}\text { Contrast: very poor, less than } 30(n=2112 ; 2.1 \%) \text {; } \\
\text { poor, } 30-60(n=4628 ; 4.7 \%) \text {; low, } 60-200 \\
(n=44601 ; 45.4 \%) ; \text { middle, } 200-500(n=35100 \text {; } \\
35.7 \%) \text {; high, } 500-1000(n=8394 ; 8.5 \%)\end{array}$ \\
\hline Residence & Base: urban ( $n=57057 ; 58 \%)$ & Contrast: rural $(n=41287 ; 42 \%)$ \\
\hline \multicolumn{3}{|l|}{$\begin{array}{l}\text { Level 2: Communities, } \mathrm{n}=285 \\
\text { Community level predictor variables }\end{array}$} \\
\hline Gini coefficient & Base: low inequality, less than $0.4(n=25,9 \%)$ & $\begin{array}{l}\text { Contrast: medium inequality, } 0.40-0.45(n=68 \text {, } \\
24 \%) \text {; high inequality, } 0.45-0.50(n=96,34 \%) ; \\
\text { very high inequality, } 0.50 \text { and above }(n=96,34 \%)\end{array}$ \\
\hline $\begin{array}{l}\text { Median income (in US\$) } \\
\text { Level 3: Regions, } n=13\end{array}$ & Mean $=176.50$ & Range $=74-1108$ \\
\hline
\end{tabular}


within 61978 households at level 2, nested within 285 communities at level 3, within 13 regions at level 4. As the response is binary, a multilevel logistic model based on a logit-link function is used, allowing for extra-binomial variation. Models were fitted using the iterative generalised least squares maximum likelihood estimator as implemented within in the MLwiN program version 1.10.0006. ${ }^{31}$ We used the marginal quasi likelihood approximation with a first order Taylor linearisation procedure being applied. ${ }^{32}$ While the marginal quasi likelihood approximation tends to be downwardly biased compared with the predictive/penalised quasi likelihood approximation, the models did not achieve convergence with the latter. The empirical models showed significant under-dispersion (0.90). Consequently, the three models, developed in a sequential order, allowed for underdispersion. We will now discuss the results from these models.

\section{RESULTS}

Table 2 presents the results for models 1 and 2 (all estimates are in logits) along with the odds ratios (OR) and their respective $95 \%$ confidence intervals. While model 1 is a null model with no predictor variables in the fixed part and a random variance component for households, communities and regions, model 2 presents estimates for individual and household predictor variables in the fixed part model and a random variance component for households, communities and regions. Apart from age and education, the remaining individual predictors are specified as indicator dummy variables. The constant (the base category), in model 2 , represents a rural man, aged 45 , who is living with a partner or married, belongs to the non-ethnic group with eight years of education and is employed belongs to the very high income category with private health insurance. The reference groups, in other words, is seen to be the "best" group with a $1.1 \%$ probability of reporting poor health.

Adjusting for age, sex, marital status, ethnicity, employment status, urban-rural residence, education, and type of health insurance, a strong relation between individual self rated poor health and household income was observed. Importantly, the health-income relation was not simply patterned across poor compared with non-poor household income groups, rather a strong income gradient in self rated health was observed, with the very poor most likely to report poor health (OR $=2.94 ; 95 \% \mathrm{CI}: 2.22$ to 3.90$)$ followed by poor $(\mathrm{OR}=2.79 ; 95 \% \mathrm{CI}: 2.17$ to 3.60$)$, low $(\mathrm{OR}=2.07 ; 95 \%$ CI: 1.64 to 2.60$)$, middle ( $\mathrm{OR}=1.74 ; 95 \% \mathrm{CI}: 1.39$ to 2.18$)$, high $(\mathrm{OR}=1.38 ; 95 \% \mathrm{CI}: 1.08$ to 1.76$)$. Figure 1 presents the graded relation between individual self rated poor health and household income.

The random part results in model 1 (table 2) suggested that variations between communities and regions were statistically significant. This variation remained significant, even after controlling for a range of individual predictors, including income, and after allowing for household level clustering. Stated differently, while individual self rated poor

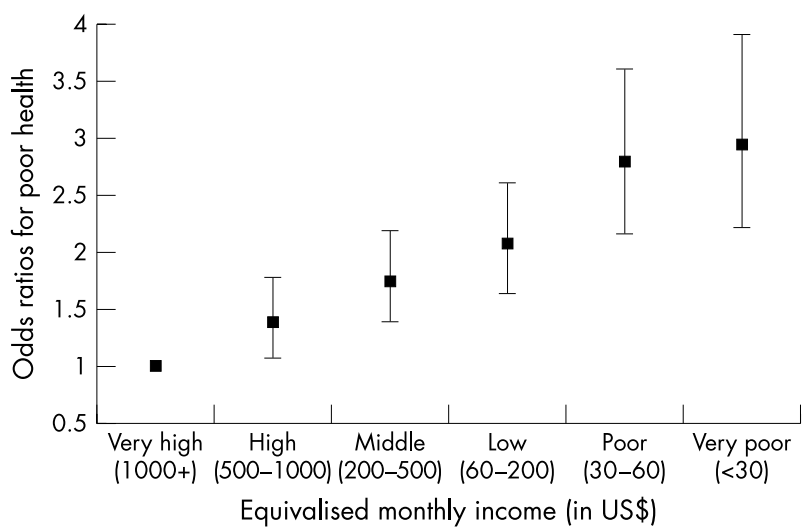

Figure 1 Average relation between household income and poor self rated health expressed in terms of odds ratios along with their $95 \%$ confidence intervals (reference group: households with an equivalised monthly income of US\$1000 and above).

Table 2 Multilevel logit regression estimates based on a four level binomial logit model for a null model with no predictor variables in the fixed part and a random variance component for households, communities, and regions (model 1); and for a model with individual and household predictor variables in the fixed part model and a random variance component for households, communities, and regions (model 2)

\begin{tabular}{lll}
\hline Fixed parameters & Model 1 & Model 2 \\
\hline Constant & -2.39 & -4.412 \\
Age & & $0.042(0.000)$ \\
Female & & $0.252(0.028)$ \\
Single & & $0.030(0.036)$ \\
Separated/divorced & $-0.253(0.040)$ \\
Widowed & & ${ }^{*}-0.070(0.056)$ \\
Ethnic & & $-0.073(0.004)$ \\
Years of education & $1.080(0.143)$ \\
Very poor & $1.027(0.129)$ \\
Poor & & $0.725(0.116)$ \\
Low income & & $0.553(0.115)$ \\
Middle income & $0.324(0.124)$ \\
High income & & $0.559(0.074)$ \\
Public health insurance & $0.274(0.083)$ \\
Other health insurance & $0.328(0.070)$ \\
Unemployed & & $0.489(0.032)$ \\
Inactive & & $0.145(0.032)$ \\
Urban & & $0.023(0.012)$ \\
Random parameters & & $0.067(0.010)$ \\
Level 4: between regions & & $2.332(0.061)$ \\
Level 3: between communities & & \\
Level 2: between households & $0.066(0.030)$ &
\end{tabular}

Figures in the parentheses represent the standard errors. All estimates are significant at 0.05 probability level or smaller, except those marked by * 
health is strongly correlated to individual socioeconomic status (SES), captured through a range of individual/household measures, they explain very little of the between place variation in self rated poor health in Chile. This would suggest that communities are not simply clustered along individual SES lines.

While results from model 2 suggest that communities matter, independent of individual SES, it need not matter in the same way for all income groups. We tested whether the average effects of household income on health varied across communities in such a way that community variation is greater for one income group as compared to another. The models did not converge, however, when we specified a complex variance-covariance structure based on income at the community level. Several modelling strategies were tried but we were unable to estimate a differential income effect for the different communities suggesting that perhaps the effect of income does not vary substantially across communities.

Table 3 presents the results from model 3 that assessed the contextual effect of community income inequality on self rated health, after controlling for household income, community median income and other key individual predictors. Our results suggest that community income inequality has an independent effect on health, over and above the well known effects of individual/household income. As shown in figure 2, compared with reference category of communities with least income inequality (less than 0.4 ) in the context of Chile, the remaining categories have greater odds of reporting poor health. In particular, communities with the Gini ranging between 0.4-0.45, show significantly higher odds ratio of reporting poor health $(\mathrm{OR}=1.22$, 95\% CI: 1.04 to 1.43$)$ with the excess risk

Table 3 Multilevel logit regression estimates based on a four level binomial logit model for a model with individual/household predictor variables and community level predictor variables in the fixed part model and a random variance component for households, communities and regions (model 3)

\begin{tabular}{ll}
\hline Fixed parameters & Model 3 \\
\hline Constant & -4.558 \\
Individual level covariates & $0.042(0.000)$ \\
Age & $0.253(0.028)$ \\
Female & $*-0.030(0.036)$ \\
Single & $0.280(0.052)$ \\
Separated/divorced & $-0.253(0.040)$ \\
Widowed & $*-0.072(0.056)$ \\
Ethnic & $-0.073(0.004)$ \\
Years of education & $1.063(0.144)$ \\
Very poor & $1.011(0.130)$ \\
Poor & $0.709(0.118)$ \\
Low income & $0.540(0.117)$ \\
Middle income & $0.315(0.125)$ \\
High income & $0.553(0.074)$ \\
Public health insurance & $0.267(0.084)$ \\
Other health insurance & $0.331(0.069)$ \\
Unemployed & $0.490(0.032)$ \\
Inactive & $0.150(0.032)$ \\
Urban & \\
Community level covariates & $-0.0005(0.0002)$ \\
Median income & $0.200(0.081)$ \\
Middle inequality & $0.178(0.077)$ \\
High inequality & $0.153(0.079)$ \\
Very high inequality & $0.018(0.010)$ \\
Random parameters & $0.063(0.009)$ \\
Level 4: between regions & $2.317(0.060)$ \\
Level 3: between communities & \\
Level 2: between households & \\
\hline
\end{tabular}

Figures in parentheses represent the standard errors. All estimates are significant at 0.05 probability level or smaller, except those marked by *.

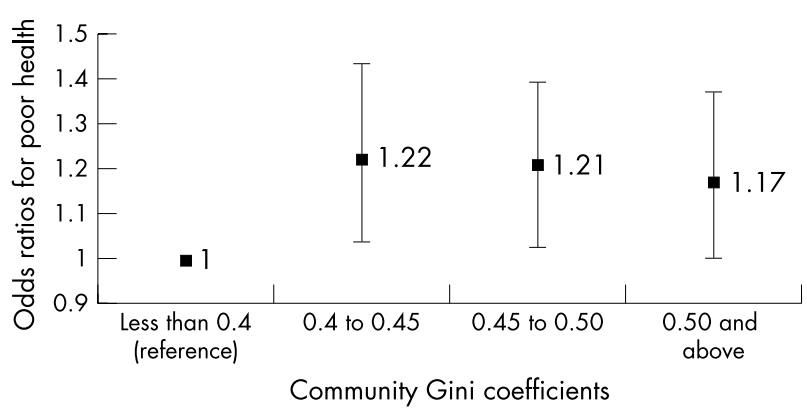

Figure 2 Relation between community income inequality and poor self rated health expressed in terms of odds ratios along with their $95 \%$ confidence intervals (reference group: communities with a Gini coefficient of less than 0.4 ).

remaining about the same for communities with income inequalities greater than 0.45 and 0.5 . Although not reported here, we also tested for a cross level interaction effect between household income groups and community income inequality, but found no significant effect. Importantly, including community Gini marginally reduces the community variation, as can be observed by comparing the random coefficients at the community level associated with constant in model 2 (0.067) and model 3 (0.063).

\section{DISCUSSION}

In this study based on a nationally representative cross section of Chile, we found evidence for both the absolute income hypothesis as well as the income inequality hypothesis. Firstly, we found a strong graded relation between household income and self rated health (the absolute income hypothesis at the individual level). The association was not simply confined to the poor; with each increment in income, the odds of reporting poor self rated health was reduced. At the same time, the relation was not linear. In Chile, as in other countries, the steepest relation between income and self rated health was observed at lower levels of income, and the curve became flatter at successively higher incomes.

Secondly, we found statistically significant community variations in self rated health that could not be explained by individual compositional factors, including household income levels. There is a tendency in the literature to attribute community differences in health to "omitted" individual compositional factors.

A third observation from our analyses was that after adjusting for household income and community income, there was evidence for an independent effect of community income inequality on poor self rated health. The magnitude of the association between community income inequality and poor self rated health was as expected smaller (fig 2) compared with the magnitude of the association between household income and health (fig l) and is consistent with the pattern found in previous multilevel studies of income inequality and health elsewhere. Factors that are more proximal to the person (such as household income) are expected to show a stronger association with individual health status, compared with factors that are more distal (such as community income inequality). Importantly, this does not mean that community determinants are somehow less important than individual determinants of health. Even small odds ratios for community level variables can imply a significant public health problem if the exposure to that condition is widespread, as is the case for community income inequality.

It is worth remarking that the association between community income inequality and poor self rated health 
was not monotonic in Chile. Rather, the empirical results from our study support the possibility of a "threshold" effect of income inequality on poor self rated health, above Gini levels of about 0.45 .

Finally, we also found a significant effect of community median income on self rated poor health such that living in communities with higher median income reduced the probability of reporting poor health.

\section{Limitations}

Our study is not without limitations. Firstly, our study was cross sectional, limiting our ability to draw causal inferences, in particular the direction of the association between household income and self rated health that could be potentially bi-directional. Secondly, while our sample size was sufficiently large to draw inferences for the population of individuals and the population of communities, at the region level, as there are only 13 regions in Chile, we need to be cautious about drawing extensive inferences on the between region variations observed in the analysis. While an alternative strategy would have been to model the 13 regions of Chile as a fixed effect, as our primary interest was not in making region specific inferences we did not specify them as "fixed effects". At the same time, we recognise that community variation should be estimated after taking into account the regions to which they belong and hence the treatment of regions as a "random effect", which is compatible with our conceptual framework. Thirdly, we have not tested whether the income inequality/health association was sensitive to the measure used. Moreover, the income data to compute Gini coefficient were derived from the same data source, CASEN, from which the health outcome and other individual characteristics were obtained. Finally, we must acknowledge the issues related to the outcome, self rated health. Self rated health could be measuring individual perception of health status as well as individual expectations of health. This can be especially problematic in the context of poor countries whereby poor people are less likely to report poor health given their lower expectations of health. ${ }^{33}$ At the same time, disadvantaged groups tend to have higher mortality. However, as the socioeconomic predictors of self rated health are in the expected direction we believe that the measure of self rated health in the context of Chile is quite appropriate.

In this paper, using an explicitly multilevel analytical framework, we investigated the relation between household income, community income, and income inequality and self rated poor health in Chile. We found evidence supporting both an absolute income effect (at the individual/household and at the community level) as well as an income inequality effect on self rated health. Our study suggests the need to test the income inequality hypothesis in additional Latin American and Asian countries, most of which are more unequal than the USA. It is possible that there is a threshold effect of income inequality on population health, such that effects become apparent only above a certain level of inequality. This may partly account for the apparent lack of an effect of income inequality in other, more egalitarian societies, such as Japan, Sweden, Denmark, and New Zealand.

\section{ACKNOWLEDGEMENTS}

We acknowledge the support of the Chilean Health Equity Initiative Program for research associated with this analysis. We are grateful to the insightful comments and suggestions of the two reviewers.

\section{Authors' affiliations}

S V Subramanian, I Kawachi, Harvard School of Public Health, Boston, USA
I Delgado, Ministry of Planning, Chile

L Jadue, Chilean Health Equity Initiative

J Vega, National Institute of Public Health, USA

\section{REFERENCES}

1 Preston SH. The changing relation between mortality and level of economic development. Population Studies 1975;29:231-48.

2 Rodgers GB. Income and inequality as determinants of mortality: an international cross-section analysis. Population Studies 1979;33:343-51.

3 Kawachi I, Kennedy BP, Wilkinson RG, eds. Income inequality and health: a reader. New York: The New Press, 1999.

4 Wilkinson RG. Income distribution and life expectancy. BMJ 1992;304:165-8.

5 Kennedy BP, Kawachi I, Prothrow-Stith D. Income distribution and mortality: cross-sectional ecological study of the Robin Hood index in the United States. BMJ 1996:312:1004-7.

6 Kaplan GA, Pamuk JW, Lynch RD, et al. Income inequality and mortality in the United States: analysis of mortality and potential pathways. BMJ 1996;312:999-1003

7 Blakely TA, Lochner K, Kawachi I. Metropolitan area income inequality and self rated health-a multilevel study. Soc Sci Med 2002;54:65-77.

8 Daly M, Duncan GA, Kaplan GA, et al. Macro-to-micro links in the relation between income inequality and mortality. Milbank Q 1998;76:315-39.

9 Fiscella K, Franks P. Poverty or income inequality as predictors of mortality: longitudinal cohort study. BMJ 1997;314:1724-8.

10 Gerdtham UG, Johannesson M. Income inequality and mortality. Malmo, Sweden: Department of Community Medicine, Malmo University Hospital, 2001.

11 Osler ME, Prescott M, Gornbaik, et al. Income inequality, individual income, and mortality in Danish adults: analysis of pooled data from two cohort studies. BMJ 2002;324:13-16.

12 Wolfson M, Kaplan G, Lynch J, et al. Relation between income inequality and mortality: empirical demonstration. BMJ 1999;319:953-5.

13 Lochner K, Pamuk ER, Makuc D, et al. State-level income inequality and individual mortality risk: a prospective multilevel study. Am J Public Health 2001;91:385-91.

14 Jones K, Duncan C, Twigg L. Evaluating the absolute and relative income hypothesis in an exploratory analysis of deaths in the Health and Lifestyle Survey. In: Boyle P, ed. The geography of health inequalities in the developed world. London: Routledge, 2002.

15 Blakely T, Kennedy BP, Kawachi I. Socioeconomic inequality in voting participation and self rated health. Am J Public Health 2001;91:99-104.

16 Blakely TA, Kennedy BP, Glass R, et al. What is the lag time between income inequality and health status? J Epidemiol Community Health 2000;54:318-19.

17 Soobader M-J, LeClere F. Aggregation and the measurement of income inequality: effects on morbidity. Soc Sci Med 1999;48:733-44.

18 Shibuya K, Hashimoto H, Yano E. Individual income, income distribution, and self rated health in Japan: cross sectional analysis of nationally representative sample. BMJ 2002;324:16-19.

19 Sturm R, Gresenz CR. Relations of income inequality and family income to chronic medical conditions and mental health disorders: national survey in USA. BMJ 2002;324:20-3.

20 Subramanian SV, Kawachi I, Kennedy BP. Does the state you live in make a difference? multilevel analysis of self-rated health in the US. Soc Sci Med 2001;53:9-19

21 Kahn RS, Wise PH, Kennedy BP, et al. State income inequality, household income, and maternal mental and physical health: cross sectional national survey. BMJ 2000;321:1311-15.

22 Diez-Roux AV, Link BG, Northridge ME. A multilevel analysis of income inequality and cardiovascular disease risk factors. Soc Sci Med 2000;50:673-87.

23 Mackenbach JP. Income inequality and population health. BMJ 2002;324:1-2

24 Kennedy BP. Income distribution, socioeconomic status and self-rated health: a US multilevel analysis. BMJ 1998;317:917-21.

25 Subramanian SV, Blakely T, Kawachi I. Income inequality as a public health concern: where do we stand? Health Serv Res 2003;38:153-67.

26 Subramanian SV, Jones K, Duncan C. Multilevel methods for public health research. In: Kawachi I, Berkman LF, eds. Neighborhoods and health. New York: Oxford University Press, 2003:65-111.

27 MIDEPLAN. Methodology-National Socioeconomic Characterizacion Household Survey. Santiago: Ministry of Planning and Cooperation, 1998.

28 Cooperation MoPa. Poverty, indigence and the impact of social expenditure on quality of life: executive report. Santiago: Ministry of Planning and Cooperation, Government of Chile, 2001.

29 Kakwani N, Wagstaff A, Doorslaer EV. Socioeconomic inequalities in health: measurement, computation, and statistical inference. Journal of Econometrics 1997:77:87-103.

30 Goldstein H. Multilevel statistical models. 2nd edn. London: Arnold, 1995.

31 Rasbash J, Browne W, Goldstein H, et al. A user's guide to MLwiN, version 2.1. London: Multilevel Models Project, Institute of Education, University of London, 2000

32 Goldstein H, Rasbash J. Improved approximations for multilevel models with binary responses. Journal of the Royal Statistical Society $A$ 1996; 159:505-13.

33 Sen AK. Health: perception versus observation. BMJ 2002;324:860-1. 